\title{
Effect of Bridging Exercise Interventions on Pain Reduction In the Elderly with Knee Osteoarthritis
}

\author{
Ratu Karel Lina ${ }^{1}$, Dwi Agustina ${ }^{2 *}$ \\ ${ }^{1,2}$ Health Polytecnic of Jakarta III, Physiotherapy Department \\ Indonesia \\ * Corresponding author's email: dwiagustinarosadi [AT] gmail.com
}

\begin{abstract}
-
Introduction: Elderly people will experience physical and psychological declines, there will also be several kinds of degenerative diseases, one of which is osteoarthritis $(\mathrm{OA})$ in the knee. Elderly people who suffer from knee OA generally experience muscle weakness, pain, and limited knee motion. This study aimed to analyze the effect of bridging exercise on reducing pain in elderly with knee $\mathrm{OA}$.
\end{abstract}

Method: The study design was quasi experiment which consisted of the treatment and the control group. The research respondents were 34 elderlies at Eastern Jakarta Village and selected by purposive sampling. The bridging exercise intervention was given for 4 weeks, 2 times a week with a duration of 30 minutes. Data analysis included univariate and bivariate analysis using independent sample t-test and paired sample t-test.

Results: The knee pain in treatment group before intervention was 8,29 and became 6,29 after intervention, whereas in control group was 7,58 and 7,53 respectively. The average difference in knee pain changed between groups was $-1,76$ with a p-value of 0.009.

Conclusion: Bridging exercise could reduce pain in knee OA of elderly. The integrated development post could apply this exercise as additional exercise in their routine activity.

Keywords: Bridging Exercise, Knee Osteoarthritis, Elderly

\section{BACKGROUND}

The achievement of development and the advancement of science and technology, including in the health sector has an impact on increasing life expectancy, which results in increases the number of elderly people worldwide [1-2]. In 2008, older people aged more than 80 years old were around 125 million [3], while the number of elderly people over 60 years of 2017 was much larger at 962 million and will increase to 2.1 billion by 2050 [4]. The number of the elderly population in Indonesia will increase from 23 million in 2015 to 61.4 million in 2045 [5].

The increasing population of the elderly has implications for the increase in degenerative diseases. Naturally the elderly population experiences a continuous aging process, which is identified by a decrease in physical and psychological declines so that it is vulnerable to degenerative diseases that can cause death $[2,6,7,8]$. Osteoarthritis is a degenerative disease commonly suffered by the elderly, which causes pain, disability and decreases the quality of life. [7, 9, 10, 11].

The incidence of OA in the world is quite high, the prevalence of OA in the world based on radiological examination reaches $3.8 \%$ in 2010, and women have a higher prevalence than men [12]. About 14 million people are thought to suffer from symptoms of knee osteoarthritis in America [10]. The prevalence of OA based on symptoms in 2007 in Korea reached 24.2\%, but the results of radiology examinations showed a higher prevalence of 37.3\% [13]. According to Irwan as cited by Sella et al., the prevalence of OA in Indonesia has also increased from $34.3 \%$ in 2002 to $36.5 \%$ in 2007 [14]. In the elderly over 70 years, it was estimated that the OA prevalence higher at around $40 \%$ and $80 \%$ of them suffer from a mild level of movement to severe.

Osteoarthritis (OA) occurs due to damage of the cartilage that protects the bone ends due to various factors such as aging, injury, obesity and inflammation, accompanied by reactive changes in the edges of the joints and subcondrial bones causing pain and impairment of movement ability and function $[11,15,16]$. Osteoarthritis can affect the largest variety of joints, including the joints in the hands, spine, knees and hips, but the most common is the knee because the joints support the human body. Elderly people who suffer from knee osteoarthritis generally experience muscle weakness, pain, and limited knee motion $[11,17,18,19]$. 
Management of Osteoarthritis in dealing with pain includes pharmacological and non-pharmacology with a focus on preventing disease and preventing the severity of the disease. Handling of non-pharmacological osteoarthritis can be in the form of weight regulation, lifestyle changes and physiotherapy actions with modalities and therapy for muscle strengthening exercises, one of which is bridging exercise [16, 20,21,22]. Currently bridging exercise is more widely used to restore muscle around the lumbar vertebrae and pelvic column, especially stroke patients to train postural balance for stroke patients [23], while treating pain in OA patients is still rare. This study aimed to analyze the effect of bridging exercise on pain in elderly suffering knee osteoarthritis.

\section{METHODOLOGY}

This study used the Quasi Experiment design by conducting pre and post-tests in the treatment and control groups. The respondents of this study were a participant of the Integrated Development Post in the Eastern Jakarta, which were selected by purposive sampling. The sample size in this study for each group was 17 , so the total number of samples was 34 . Determination of respondents based on inclusion criteria, which included minimum 45 years of age, experiencing knee OA, physically healthy in the sense of still being able to do daily activities without devices/ supporting aids, good communication and cognitive function, and willing to be a respondent. Elderly who had post fracture and severe knee pain, severe pain so unable to do the exercise was excluded from the study. Respondents were asked for their prior written approval before participating in the study. This research protocol has received ethical approval from the Ethics Commission of Jakarta III Health Polytechnic Ministry of Health.

Knee OA assessment was done by examining clinical symptom and palpation, as well as The Western Ontario and McMaster Universities Arthritis Index (WOMAK) measurement. The level of pain was measured with Visual Analog Scale (VAS) and done twice, before the intervention and after all intervention complete. The treatment group was given a bridging exercise intervention which was initiated by warming up, followed by core training and closed with cooling. The core training consisted of hip bridge and single leg bridge up exercises which was carried out for approximately 20 minutes. While warming up and cooling was done 5 minutes for each, so that the total duration of the intervention was 30 minutes. Interventions were given 2 times a week for 8 weeks. The control group was not given any treatment, but at the end of the study, the bridging exercise leaflet was given. Data analysis includes univariate and bivariate with independent sample $t$ test and paired sample t test as the data was normally distributed.

\section{RESULT}

In general, the distribution of demographics between treatment and control groups was not much different. In table 3.1 , it appears that the sex of the respondents was dominated by women in both the treatment and control groups. The age of the respondents mostly ranged from 60 - 69 years, but in the control group the proportion of respondents aged 50-59 and 60-69 was equal to $47 \%$, as shown in table 3.2 .

Table 3.1. Gender Frequency Distribution

\begin{tabular}{ccccccc}
\hline \multirow{2}{*}{ Group } & \multicolumn{2}{c}{ Male } & \multicolumn{2}{c}{ Female } & \multicolumn{2}{c}{ Jumlah } \\
\cline { 2 - 7 } Treatment & Frequency & $\%$ & Frequency & $\%$ & Frequency & $\%$ \\
Control & 4 & 24 & 13 & 76 & 17 & 100 \\
Total & 4 & 24 & 13 & 76 & 17 & 100 \\
\hline
\end{tabular}

Table 3.2. Age Group Frequency Distribution

\begin{tabular}{ccccccccc}
\hline \multirow{2}{*}{ Group } & \multicolumn{2}{c}{$40-49$ years } & \multicolumn{2}{c}{$50-59$ years } & \multicolumn{2}{c}{$60-69$ years } & \multicolumn{2}{c}{ Total } \\
\cline { 2 - 8 } & Frequency & $\%$ & Frequency & $\%$ & Frequency & $\%$ & Frequency & $\%$ \\
\hline \multirow{2}{*}{ Treatment } & 3 & 18 & 5 & 29 & 9 & 53 & 17 & 100 \\
Control & 1 & 6 & 8 & 47 & 8 & 47 & 17 & 100 \\
Total & 4 & 12 & 13 & 38 & 17 & 50 & 34 & 100 \\
\hline
\end{tabular}

Table 3.3 shows knee pain before intervention in the treatment and control groups was not much different from the mean of 8.29 in the treatment group and 7.59 in the control group with the probability value of 0.081 . This indicated that both groups had comparable pain levels before being given intervention. 
Table 3.3. Comparison of Pain between Treatment and Control Groups before Intervention

\begin{tabular}{ccccc}
\hline Group & Mean \pm SD & Min -Max & Mean Difference \pm SD & P-Value \\
\hline Intervention & $8,29 \pm 1,26$ & $5-10$ & \multirow{2}{*}{$0,71 \pm 0,39$} & \multirow{2}{*}{0,081} \\
Kontrol & $7,59 \pm 1,00$ & $6-10$ & & \\
\hline
\end{tabular}

Table 3.4 shows, after being given interventions, the treatment group showed lower pain, which was 6.29, when compared to the control group which reached $7.35(\mathrm{p}=0.450)$. The paired t-test results also showed a significant change in pain in the treatment group with a $\mathrm{p}$ value of 0.002 . Whereas in the control group, it did not show statistically significant changed with a $\mathrm{p}$ value of 0,450 . Pain levels in treatment group were also much reduced when compared to the control group, as seen in Figure 3.1 .

Table 3.4. Comparison of Pain Between Treatment and Control Groups

\begin{tabular}{|c|c|c|c|c|c|c|}
\hline \multirow{2}{*}{ Group } & \multicolumn{2}{|c|}{ Before intervention } & \multicolumn{2}{|c|}{ After intervention } & \multirow{2}{*}{$\begin{array}{c}\text { Mean } \\
\text { difference }\end{array}$} & \multirow{2}{*}{ P-Value } \\
\hline & Mean & Min -Max & Mean & Min -Max/ & & \\
\hline Intervention & $8,29 \pm \underline{\mathrm{SD}}$ & $5-10$ & $6,29 \pm 1,36$ & $4-8$ & $-2,00$ & 0,002 \\
\hline Kontrol & $7,59 \pm \mathrm{SD}$ & $5-9$ & $7,35+1,27$ & $4-9$ & $-0,24$ & 0,450 \\
\hline
\end{tabular}

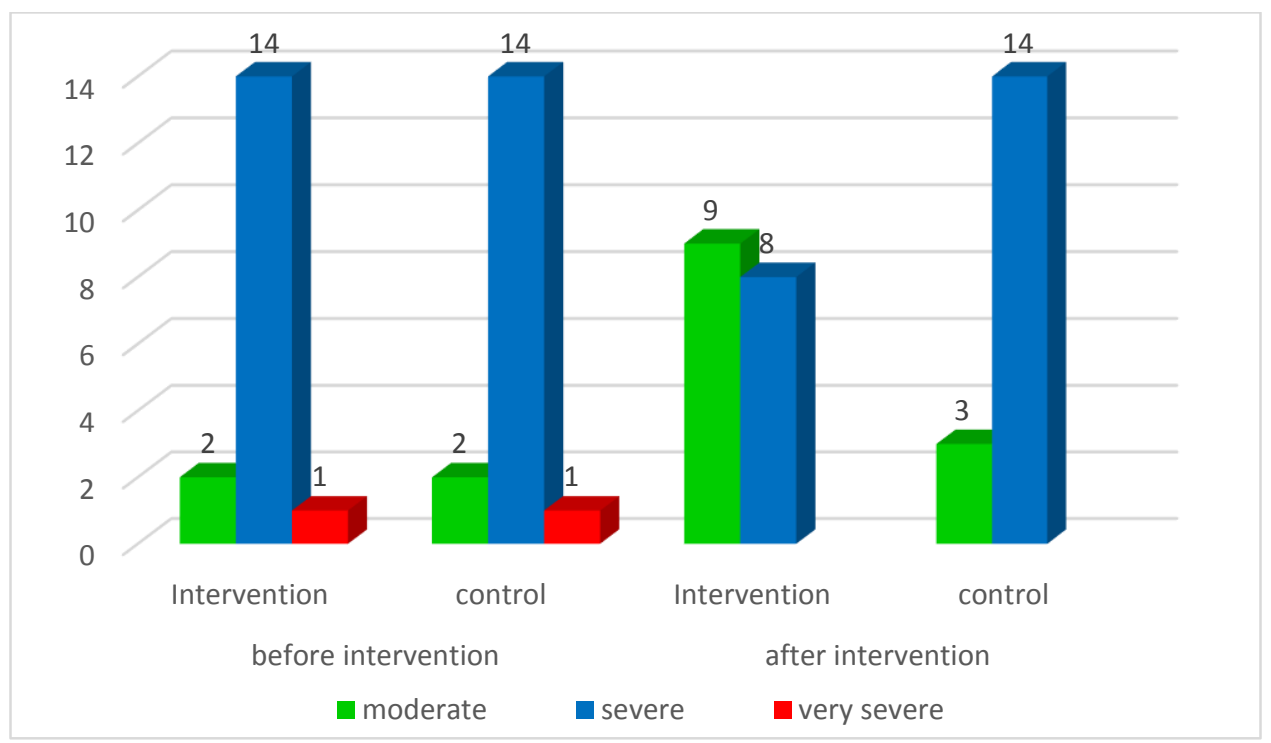

Figure 3.1. Comparison of pain level between the treatment and control groups

Changed in pain after intervention in treatment and control groups in Table 5 showed a significant difference with the $\mathrm{p}$ value of 0.009 .

Table 3.5. Comparison of Difference in Mean Changed between Groups

\begin{tabular}{lcccc}
\hline Variable & $\begin{array}{c}\text { Mean } \\
\text { difference }\end{array}$ & $\begin{array}{c}\text { 95\% CI of the Difference } \\
\text { Lower }\end{array}$ & Upper & P-Value \\
\hline $\begin{array}{l}\text { Difference in mean changed } \\
\text { between groups }\end{array}$ & $-1,76$ & -3.06 & $-0,47$ & 0,009 \\
\hline
\end{tabular}

\section{DISCUSSION}

Knee OA is a degenerative disease that causes damage and erosion of joint cartilage, ligament laxity and muscle weakness and pain in the area of knee $[24,25,26]$. Knee OA generally has a functional disorder that affects its activities, especially in 
carrying out daily activities including walking, moving from one place to another that are needed to maintain independence and life quality [7, 10, 26, 27].

The majority of respondents in this study were women with a proportion of $76 \%$ and only $24 \%$ of men. Various studies show gender is the OA risk factor that cannot be controlled, women possess a greater risk than men, especially during menopause $[26,28]$. Distinction in knee anatomy, kinematic, and hormonal factors have an important role on the high risk of knee OA in women. Differences in knee anatomy between female and male include the closer distance of the femur, thinner patella, larger quadriceps angle, and differences in the size of the tibial condyle [29].

This study aimed to analyze the effect of bridging exercise on pain in elderly with knee OA. The results showed that giving bridging exercises for 8 weeks was able to reduce pain in the treatment group by $24 \%$ from an average score of 8.29 to 6.29 . Conversely significant change was not seen in the control group. The bridging exercise that consisted of hip bridge and single leg bridge up were a strengthening movement of quadriceps and hamstring muscles, resulting in biomechanical optimization which reduces the level of joint pressure, local stress in the articular cartilage or balance disorders [30]. Strong quadricep muscles increase the stability of the knee joint in the right position, dampen the shock that is channelled to the joint and minimize its impact to a wider area. This exercise also controls the femur in the knee joint which affects other bones in the joints so that it works synergistically [31]. The research conducted by Mahmoud et al. who provided a quadriceps isometric exercise intervention for 12 weeks succeeded in reducing knee pain, increasing quadriceps muscle strength in obese women with knee OA [30]. Anwer \& Alghadir who gave similar interventions with a shorter time of 8 weeks also found an increase in quadriceps muscle strength and functional disability and decreased pain [31]. Another study conducted by N. who also provided 6 months of isometric quadriceps, hamstring training also showed improvement in quadriceps muscle strength, reduction of functional pain and disability [32]. In a study comparing the effects of adding home quadriceps training for 8 weeks on patients who were given nonsteroidal anti-inflammatory drugs (NSAIDs) it was found that home quadriceps exercise could reduce pain faster compared to patients who only took the medication [33].

Pain reduction in research may not only be due to muscle strengthening, but could also be due to psychological factors and adaptation of the central nervous system. Bridging exercise performed by the elderly could affect the work of the cerebral cortex in cognitive and emotional aspects, resulting in positive perception and relaxation. Bridging exercise could be indirectly helping maintain the balance of body homeostasis through the hypothalamic-pituitary- adrenal (HPA) Axis, to produce corticotrophin releasing factor (CRF). Furthermore CRF stimulates the pituitary gland to reduce adrenocorticotropin hormone (ACTH) production, so that endorphin production increases, which then decreases cortisol production and other stress hormones, result in pain decreases $[34,35]$. The provision of bridging exercise interventions is carried out in a relaxed, family atmosphere in the local area, so that respondents can do the exercises feeling happy and relaxed. This has a good impact on increasing adaptation levels and excitatory levels, so respondents respond positively. When the respondent has a positive perception there will be a condition of relaxation and neurological or endocrine chemical changes in the body so that it will be easier to accept the healing suggestions given.

\section{CONCLUSIONS}

Bridging exercises exercises given for 8 weeks can reduce pain levels in the elderly with knee OA. This exercise can be used as an additional exercise in Posbindu routine activities conducted in East Jakarta. Similar research can be done to help patients with knee OA pain in the elderly by improving the selection system based on radiological examination. The type of exercises can also be added to get maximum results. In addition, functional measurements and muscle strength could also be done in addition to the impact of training, not just pain.

\section{REFERENCIES}

[1] Pusat Data dan Informasi Kementerian Kesehatan RI, "Gambaran kesehatan lanjut usia di Indonesia,” Buletin Jendela Data \& Informasi Kesehatan, vol. Semester I, Jakarta, pp. 1-18, Jul-2013.

[2] World Health Organization, World Report on Ageing and Health. Geneva: WHO, 2015.

[3] World Health Organization, "Ageing and health," 2018. [Online]. Available: http://www.who.int/news-room/factsheets/detail/ageing-and-health. [Accessed: 11-Nov-2018].

[4] United Nation Department of Economic and Social Affairs Population Division, World Population Ageing 2017 Highlights (ST/ESA/SER.A/397). New York: United Nation, 2017.

[5] Badan Pusat Statistik, Proyeksi Penduduk Indonesia 2015-2045 - Hasil SUPAS 2015; Indonesia Population Projection 2015-2045 - Result of SUPAS 2015. Jakarta: Badan Pusat Statistik, 2018.

[6] G. R. Boss and J. E. Seegmiller, “Age-related physiological changes and their clinical significance.,” West. J. Med., vol. 135, no. 6, pp. 434-40, 1981.

[7] C. Palazzo, C. Nguyen, M. M. Lefevre-Colau, F. Rannou, and S. Poiraudeau, "Risk factors and burden of osteoarthritis," 
Ann. Phys. Rehabil. Med., vol. 59, no. 3, pp. 134-138, 2016.

[8] S. Amarya, K. Singh, and M. Sabharwal, “Ageing process and physiological changes,” in Gerontology, G. D’Onofrio, Ed. London: IntechOpen, 2018.

[9] M. A. Greene and Richard F. Loeser, “Aging-related inflammation in osteoarthritis,” Osteoarthr. Cartil., vol. 23, no. 11, pp. 1966-1971, 2015.

[10] E. R. Vina and C. K. Kwoh, "Epidemiology of osteoarthritis: Literature update," Curr. Opin. Rheumatol., vol. 30, no. 2, pp. 160-167, 2018.

[11] A. M. Valdes and J. Stocks, “Osteoarthritis and ageing," Eur. Med. J., vol. 3, no. 1, pp. 116-123, 2018.

[12] M. Cross et al., "The global burden of hip and knee osteoarthritis: Estimates from the global burden of disease 2010 study," Ann. Rheum. Dis., vol. 73, no. 7, pp. 1323-1330, 2014.

[13] C. Liu, Q. Wan, W. Zhou, X. Feng, and S. Shang, "Factors associated with balance function in patients with knee osteoarthritis: An integrative review,” Int. J. Nurs. Sci., vol. 4, no. 4, pp. 402-409, 2017.

[14] D. A. Sella, Sahruddin, and K. Ibrahim, "Hubungan intensitas sholat, aktivitas olahraga dan riwayat kebiasaan mandi malam dengan penyakit osteoartritis pada lansia di Panti Sosial Tresna Werdha Minaula Kota Kendari tahun 2017,” J. Mhs. Kesehat. Masy., vol. 2, no. 6, pp. 1-9, 2017.

[15] G. S. Man and G. Mologhianu, “Osteoarthritis pathogenesis - a complex process that involves the entire joint.," J. Med. Life, vol. 7, no. 1, pp. 37-41, 2014.

[16] J. C. Mora, R. Przkora, and Y. Cruz-Almeida, "Knee osteoarthritis: Pathophysiology and current treatment modalities," J. Pain Res., vol. 11, pp. 2189-2196, 2018.

[17] M. J. Lespasio, N. S. Piuzzi, M. E. Husni, G. F. Muschler, A. J. Guarino, and M. A. Mont, "Knee osteoarthritis: A primer," Perm. J., vol. 21, no. 16-183, 2017.

[18] Daniel L. Riddle and P. W. Stratford, "Knee pain during daily tasks, knee osteoarthritis severity, and widespread pain," Phys. Ther., vol. 94, no. 490-498, pp. 62-63, 2014.

[19] J. F. M. Holla et al., "Determinants of range of joint motion in patients with early symptomatic osteoarthritis of the hip and/or knee: An exploratory study in the CHECK cohort," Osteoarthr. Cartil., vol. 19, no. 4, pp. 411-419, 2011.

[20] M. Khan, A. Adili, M. Winemaker, and M. Bhandari, "Management of osteoarthritis of the knee in younger patients," CMAJ, vol. 190, no. 3, pp. E72-E79, 2018.

[21] S. P. Yu and D. J. Hunter, "Managing osteoarthritis,” Aust. Prescr., vol. 38, no. 4, pp. 115-119, 2015.

[22] T. E. McAlindon et al., "OARSI guidelines for the non-surgical management of knee osteoarthritis," Osteoarthr. Cartil., vol. 22, no. 3, pp. 363-388, 2014.

[23] J. Lim, S. Lee, D. Lee, and J. Park, "The effect of a bridge exercise using the abdominal drawing-in maneuver on the balance of chronic stroke patients," J. Phys. Ther. Sci., vol. 24, no. 8, pp. 651-653, 2012.

[24] R. Gheno, J. Cepparo, C. Rosca, and A. Cotten, "Musculoskeletal disorders in the elderly," J. Clin. Imaging Sci., vol. 2, no. 1 , p. 39, 2012.

[25] D. Chen et al., "Osteoarthritis: Toward a comprehensive understanding of pathological mechanism," Bone Res., vol. 5, no. September 2016, 2017.

[26] A. Litwic, M. H. Edwards, E. M. Dennison, and C. Cooper, "Epidemiology and burden of osteoarthritis," Br. Med. Bull., vol. 105, no. 1, pp. 185-199, 2013.

[27] T. Neogi, "The epidemiology and impact of pain in osteoarthritis," Osteoarthr. Cartil., vol. 21, no. 9, pp. 1145-1153, 2013.

[28] K. D. Allen, Y. M. Golightly, C. Hill, C. Hill, C. Hill, and C. Hill, "Epidemiology of osteoarthritis: state of the evidence," Curr. Opin. Rheumatol., vol. 27, no. 3, pp. 276-283, 2015.

[29] S. L. Hame and R. A. Alexander, "Knee osteoarthritis in women," Curr. Rev. Musculoskelet. Med., vol. 6, no. 2, pp. 182$187,2013$.

[30] W. S. Mahmoud, R. K. Elnaggar, A. S. Ahmed, and W. S. Mahmoud, "Influence of isometric exercise training on quadriceps muscle architecture and strength in obese subjects with knee osteoarthritis," Int J Med Res Heal. Sci, vol. 6, no. 3, pp. 1-9, 2017.

[31] S. Anwer and A. Alghadir, "Effect of isometric quadriceps exercise on muscle strength, pain , and function in patients 
with knee osteoarthritis : A randomized controlled ttudy," J. Phys. Ther. Sci., pp. 2-5, 2014.

[32] A. N, "An intervention study on the effectiveness of isometric quadriceps hamstrings exercise in the treatment of osteoarthritis , knee joint," Int. J. Orthop. Sci. adults, vol. 4, no. 2, pp. 1010-1014, 2018.

[33] C. M. Walid et al., "Effect of quadriceps strengthening exercise on reduction of pain in knee osteoarthritis," Bangladeh Med. J., vol. 41, no. 3, pp. 19-22, 2012.

[34] L. Arborelius, M. J. Owens, P. M. Plotsky, and C. B. Nemeroff, "The role of corticotropin-releasing factor in depression and anxiety disorders," J. Endocrinol., vol. 160, no. 1, pp. 1-12, 1999.

[35] J. Sidabutar, "Menurunkan dismenoreaa primer melalui hipnoterapi pada siswi sekolah menengah pertama," Padjadjaran Nurs. J., vol. 3, pp. 111-118, 2015. 